\title{
Exceptional response and multisystem autoimmune-like toxicities associated with the same $T$ cell clone in a patient with uveal melanoma treated with immune checkpoint inhibitors
}

\author{
Suthee Rapisuwon ${ }^{1,5^{*}}$ D, Benjamin Izar $^{2}$, Cory Batenchuk ${ }^{3}$, Alexandre Avila ${ }^{3}$, Shaolin Mei², Peter Sorger ${ }^{4}$, \\ Jerry M. Parks ${ }^{6}$, Connor J. Cooper ${ }^{6}$, David Wagner ${ }^{5}$, Jay C. Zeck ${ }^{5}$, Aline J. Charabaty ${ }^{5}$ and Michael B. Atkins ${ }^{1,5}$
}

\begin{abstract}
Balancing the potential for durable remissions with autoimmune-like toxicities is a key clinical challenge in the use of immune checkpoint inhibitors $(\mathrm{ICI})$. Certain toxicities are associated with an increased response rate; however, the molecular underpinnings of this association are poorly understood. Here, we report a patient with wide spread uveal melanoma who had an exceptional response to treatment with ipilimumab and nivolumab, but suffered severe immune-related sequelae, including central serous retinopathy with retinal detachment, tinnitus, and vitiligo resembling Vogt-Koyanagi-Harada disease, and refractory enteritis. TCR-sequencing of the primary tumor, a hepatic metastasis, duodenal biopsy and peripheral blood mononuclear cells, identified the identical T cell clone in all four tissues. This case provides preliminary evidence for cross-reactivity as a mechanism for the association between effect and toxicity of ICls.
\end{abstract}

\section{Introduction}

Uveal melanoma (UM) comprises $<3 \%$ of all melanomas with an incidence of 5-10 cases/million [1] and underlying biology that is distinct from cutaneous melanoma (CM). In the last decade, the interrogation of the genetic landscape [2] and advances in immuno-oncology [3] have led to a remarkable improved survival rate of 40$60 \%$ [4] in patients with metastatic CM. In contrast, patients with UM rarely (ORR 0-2.6\%) [5, 6] respond to ICIs, including anti-CTLA-4 and anti-PD1 monotherapies, and show low response rate (15.8\%) to the combination [7]. Intrinsic resistance to ICIs in UM may be related to various mechanisms, including a low somatic mutation rate [8] and paucity of tumor infiltrating lymphocytes [9]. In CM, ICI-related skin toxicities, such as

\footnotetext{
* Correspondence: sr905@georgetown.edu

'Department of Oncology, Lombardi Comprehensive Cancer Center,

Georgetown University Medical Center, 3970 Reservoir Rd NW, New Research Building Suite E 501, Washington, DC 20057, USA

${ }^{5}$ Medstar Georgetown University Hospital, Washington, DC, USA

Full list of author information is available at the end of the article
}

rash and vitiligo, correlate with increased tumor response and prolonged survival [10]. The immunological underpinnings for this phenomenon in patients remain poorly understood. Delineating underlying mechanisms may help to identify approaches for dissociating treatment benefits and risks.

Here we report a patient with metastatic UM who experienced an exceptional response to dual blockade of PD-1 and CTLA-4. This response was accompanied by severe and unique immune-related adverse events (irAEs). Integrated analysis of several tissues, including primary tumor, a liver metastasis, inflamed duodenum and peripheral blood using whole-exome, transcriptome and $\mathrm{T}$ cell receptor (TCR) sequencing, and multiplexed immunofluorescence identified a dominant $\mathrm{T}$ cell clone. This report suggests that tumor-reactive $\mathrm{T}$ cell clones may play a role in mediating toxicity in healthy tissues.

(c) The Author(s). 2019 Open Access This article is distributed under the terms of the Creative Commons Attribution 4.0 International License (http://creativecommons.org/licenses/by/4.0/), which permits unrestricted use, distribution, and reproduction in any medium, provided you give appropriate credit to the original author(s) and the source, provide a link to the Creative Commons license, and indicate if changes were made. The Creative Commons Public Domain Dedication waiver (http://creativecommons.org/publicdomain/zero/1.0/) applies to the data made available in this article, unless otherwise stated. 


\section{Case description}

A 60-year-old woman was diagnosed with $18 \times 14 \mathrm{~mm}$ UM of the right eye and underwent enucleation in 2009. Pathology confirmed UM with monosomy 3 and 8q amplification. She developed a solitary hepatic metastasis in 2014 and underwent right hepatectomy. A multi-gene panel analysis of the tumor showed somatic BAP-1 and GNA11 mutations. She developed extensive metastases 9 months later with multiple hepatic, bone and lung lesions, and elevation of lactate dehydrogenase (LDH) > $1300 \mathrm{U} / \mathrm{L}$. She received combination nivolumab and ipilimumab therapy. After two infusions, she developed central serous retinopathy of the left eye with retinal detachment, tinnitus and vitiligo resembling Vogt-Koyanagi-Harada (VKH) disease, an ocular autoimmune syndrome (Fig. 1c). CT scan at 12 weeks demonstrated significant reduction in hepatic metastases (Fig. 1a and b), and disappearance of lung and bone metastases. LDH level initially rose and then normalized (Fig. 1f). She continued on nivolumab monotherapy and experienced a near-complete response, but developed grade 3 duodenitis (Fig. $1 \mathrm{~d}$ and e) requiring prolonged high-dose immunosuppressive therapy, including high-dose prednisone, followed by infliximab, and vedolizumab with eventual resolution. The clinical antitumor response persisted for over 1 year from treatment initiation and over 9 months from the last dose of immunotherapy. Unfortunately, she developed progressive brain and liver metastases after 1.5 year. Nivolumab monotherapy was resumed resulting in a mixed response and additional skin and eye toxicity, preventing further treatment. Due to overall declining health, the patient decided for supportive care and died 6 months after reinitiating original systemic therapy.

\section{Results}

\section{Molecular and immunologic analyses}

Tumor DNA from the liver lesion was sequenced at a depth of $60 \mathrm{X}$ and the PMBC sample was sequenced at $30 \mathrm{X}$ depth. Following data analysis and integration, a total of 111 somatic SNPs were identified (Additional file 1: Figure S1a). Twenty-one (19\%) were predicted to be deleterious (moderate or high-impact) as they occurred within the coding region and did not result in a synonymous variant (Additional file 1: Table S1). Of these 21 mutations, only BAP1 and GNA11 were identified in the NCI Genomic Data Commons (GDC) UM dataset. The BAP1 gene, a prevalent mutation in UM [11] contained a stop-gain mutation. GNA11, a G-protein-coupled receptor, contained the Q209L mutation present in 33 of 80 UM annotated by GDC. The remaining commonly mutated genes in UM, e.g., EIF1AX, SF3B1, and GNAQ, were wild-type. None of the 21 deleterious mutations have been associated with vitiligo or VKH. The rate of SNVs resulting in potential neo-epitopes (21 SNVs) was similar to the rate described in the GDC UM dataset (median: 15) (Additional file 1: Figure S2) as well as for subjects with BAP1 mutation (median: 14) or stage III/IV disease (median: 13). In comparison, the mutation rates in CM from patients with stage III/IV disease [12] are $\sim 25$ fold greater.

To better understand the tumor microenvironment, we compared the RNA signature from the liver metastasis to the RNA signature for the 80 primary UM in GDC. Based on this comparison, the liver metastasis was predicted to have brisk immune cell infiltration (Additional file 1: Figure S3). The gene signature of the patient's sample was the top ranked sample defined by the median reading for macrophage genes (CD163, IL4R \& CD68), the 5th highest for genes associated with cytotoxic $\mathrm{T}$ lymphocytes (CD3D, CD3E, CD3EAP, CD3G, CD8A \& CD8B) and the 22nd highest for genes expressed by NK cells (SLAMF7, KLRK1 \& GZMB). Similarly, the sample was the 10th highest with respect to average expression of an IFN $\gamma$ signature (CXCL10, CXCL9, STAT1, IDO1, IFN $\gamma$ ) previously associated with response to immunotherapy [13]. Both vitiligo associated genes (PMEL, TYRP1, DCT \& MLANA) and PD-L1 had mRNA levels near the median value observed across the dataset. Of the 21 mutated loci, 10 were qualified as associated with the upper quartile of gene expression relative to the GDC dataset (TRIP11, ZNF326, PKD1L2, CHRM2, SF3B1, CSE1L, EIF1AX, CHN2, SRRM2 \& CATSPERG).

Based on RNA expression data, we subsequently investigated the immunobiology landscape of the primary eye tumor and liver tumor tissues using CycIF [14]. The primary tumor contained very few PD-L1+ stromal cells (magenta) and CD8 $+\mathrm{T}$ cells (white), with low levels of $\mathrm{CD} 11 \mathrm{~b}+$ macrophages (red) (Fig. 2). The liver tumor, despite low level of PD-L1+ stromal cells and widely expressed CD11b + macrophages, exhibited an intense immunofluorescent signal of CD8+ T cells (Fig. 2b). This finding suggests naturally occurring tumor-specific $\mathrm{T}$ cell recognition and expansion of TILs in the liver metastasis.

TCR sequencing confirmed immune involvement in the metastatic tissue prior to therapeutic intervention. There were an estimated 39,794 T cells of 218,816 nucleated cells (18\%). The clonality metric was 0.153 , indicating a clonal T-cell population against a specific tumor antigen. When compared to the CM dataset generated by Tumeh et al. [15], both T-cell abundance and T-cell clonality indicated that the patient was likely to respond to therapy given the above median values for both metrics (Fig. 3a). To better understand the TCR clones involved, the primary tumor sample, and a duodenal sample and PBMC samples collected during treatment were submitted for TCR sequencing (Adaptive). Of the top 10 sequences detected in the primary tumor sample, many were among the top TCR sequences detected in the additional samples (Fig. 3b). In particular, the "CASRVTSGGYNEQFF" amino acid 

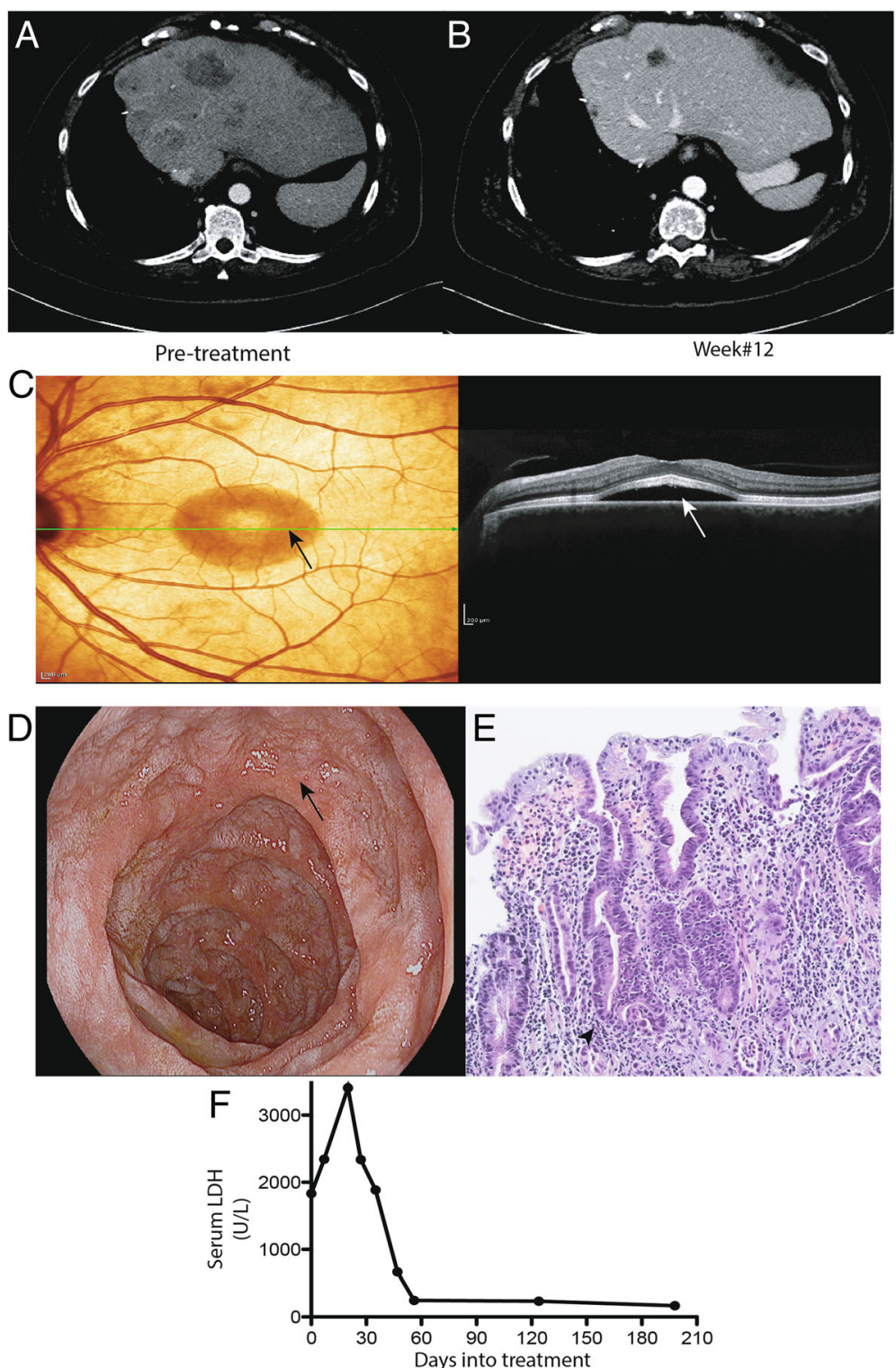

Fig. 1 Clinical Characteristics. Panel $\mathbf{a}$ and $\mathbf{b}$ depict pre- and post-treatment computed tomography of the liver with complete resolution of liver metastases. Panel $\mathbf{c}$ depicts central serous retinopathy (arrow) on fundoscopic examination and Optical Coherence Tomography (OCT). Panel $\mathbf{d}$ and $\mathbf{e}$ shows endoscopic and pathologic findings of post-treatment duodenitis (arrow) with marked acute inflammatory cell infiltrate involving most of the glandular epithelium. The infiltrate is predominantly within deep crypt spaces (arrowhead). Panel $\mathbf{f}$ shows decline of serum LDH shortly after immunotherapy were initiated

sequence derived from TCRBV19-01 represented the most prevalent clone in the metastatic tumor, PBMC and duodenal samples. In the primary lesion obtained several years prior, it was the 4th highest sequence detected. We did not characterize the specificity of this TCR sequence further.

To determine the potential for each candidate neoantigen to be presented by the subject's class-I MHC and bind to the identified clonal T-cells, we performed in-silico binding affinity predictions between the HLA allele (HLA-A*24:02) and all possible 8- to 11-mer peptides that included mutation-related residues. Using NetMHC 4.0 [16] and NetMHCpan 4.0 [17], none of the peptide candidates was predicted to be a suitable binder $\left(\mathrm{IC}_{50} \leq 500 \mathrm{nM}\right)$ to the patient's HLA allele.

\section{Pharmacovigilance}

A search of the BMS safety database revealed 8 cases with the reported term of $\mathrm{VKH}$. Two cases involved ipilimumab monotherapy, one involved ipilimumab in combination with nivolumab, three involved nivolumab monotherapy, one was treated with nivolumab followed 


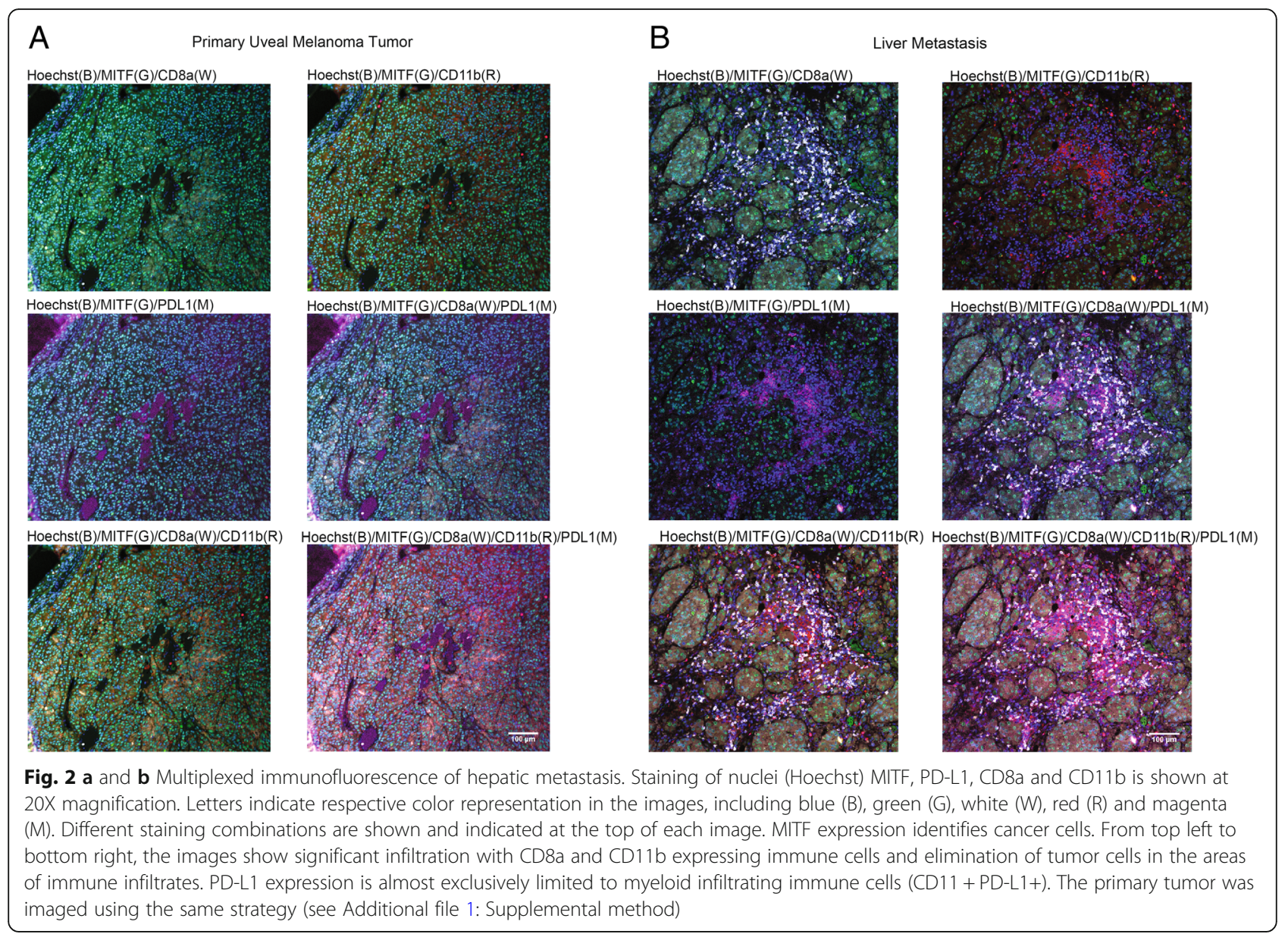

by ipilimumab, and another nivolumab followed by vemurafenib. Five of these cases have been reported in the literature [18-21]. Five were from Japan, two from the USA, and one from Germany. Two of the nivolumab monotherapy cases from Japan were patients with NSCLC. The other six cases had melanoma. No cases had UM.

\section{Discussion}

This exceptional response of the patient's UM to combined ICI illustrates the potential critical role of clonal expansion of TILs in achieving clinical benefit from immunotherapy. That the same CD8+ TIL clones in the primary tumor expanded in the metastases suggests that these TILs were directed against the same antigen on the tumor. Detection of this clone in PBMC and within the duodenum, a site of irAE, strongly suggests that the antitumor effects and toxicity were mediated by the same $\mathrm{T}$ cell clone. The involvement of barrier tissues (skin, gastrointestinal mucosa) by irAEs beyond drug exposure supports the possibility that adverse effects may be mediated by tissue-resident memory $\mathrm{T}$ cells (TRM) [22] Further, the presence of a specific TCR clone in the primary eye tumor, liver metastasis and site of enteritis and the occurrence of $\mathrm{VKH}$ and vitiligo suggest that the clone was directed against a shared antigen/epitope rather than a tumor neoantigen. In the absence of neoantigens that strongly bind class-I MHC, the irAEs may stem from enhanced TCR interactions with self-antigens arising from ICI therapy.

When anti-tumor reactivity is directed against a shared antigen the therapeutic index may be narrow, with toxicity occurring nearly simultaneously with antitumor response, as in this case. This observation has been recently reported in another case of metastatic UM that achieved a durable major response to the combination ICI in association with autoimmune hepatitis, uveitis and exocrine pancreatic insufficiency [23].

While activation of quiescent immune-reactive $\mathrm{T}$ cells resident in non-tumor tissue is purported to be the mechanism of autoimmune thyroiditis, colitis, and other typical toxicities of ICI, the irAEs in both cases of advanced UM suggest that there was cross-reactivity of $\mathrm{T}$ cell immunity against an antigen that was shared between the UM and the contralateral uvea, the skin and non-tumor organs. That the duodenitis was unresponsive to steroids and 


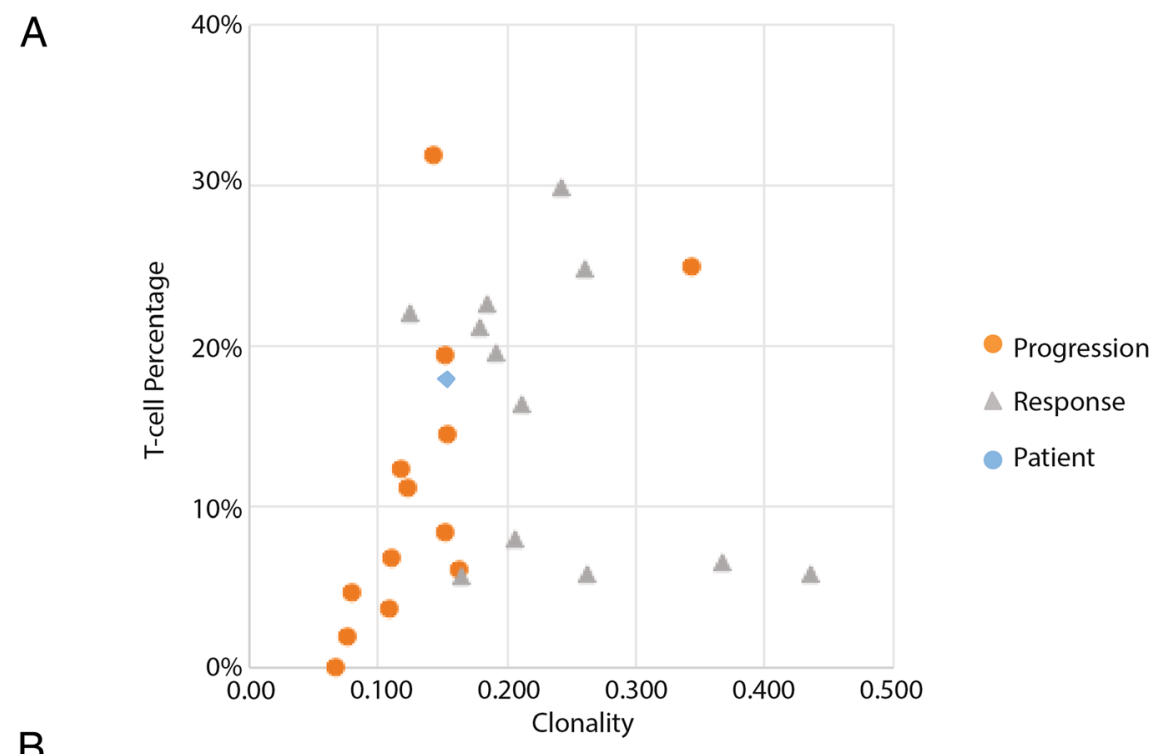

\begin{tabular}{|l|c|c|c|c|}
\hline T-Cell Receptor Sequence & Hepatic Metastasis & PBMCs & Duodenum & Primary Eye Tumor \\
\hline CASRVTSGGYNEQFF & 1 & 1 & 1 & 4 \\
\hline CASSPGDSHASNTGELFF & 2 & 16 & 250 & 148 \\
\hline CSAGEEGYEQYF & 3 & 30 & - & 60 \\
\hline CASSQNALGLAGTDTQYF & 4 & 214 & - & 3 \\
\hline CASSSRRDNTGELFF & 5 & 39 & 759 & - \\
\hline
\end{tabular}

Fig. 3 Expansion of clonal T-cells from Primary Uveal Melanoma. Panel a depicts TCR clonality metrics in the TME relative to published result regarding the association of these metrics with recently reported responses to anti-PD1 therapy in cutaneous melanoma [15]. Panel $\mathbf{b}$ depicts amino acid sequence of corresponding uniquely rearranged variable TCR $\beta$-chain regions in primary eye tumor, hepatic metastasis, PBMCs, and inflamed duodenum. TCR sequence, "CASRVTSGGYNEQFF" was expanded from the primary eye tumor ( $4^{\text {th }}$ most prevalent) to become the most abundant clone in hepatic metastasis, and peripheral blood that persisted more than 6 months after treatment initiation. The same clone is seen as the top infiltrating T-cell clone in duodenal crypt inflammation

infliximab, but did respond promptly to vedolizumab [24], a monoclonal antibody to integrin $\alpha 4 \beta 7$ (LPAM-1), which blocks $\mathrm{T}$ cell infiltration into the GI tract, suggests that her GI toxicity derived from circulating $\mathrm{T}$ cells that trafficked into the GI tract following expansion in a distant site, such as the tumor. A similar pathophysiology may occur in the cases of extreme cardiotoxicity, where expanded $\mathrm{T}$ cell clones that were present in the tumor were also identified in the inflamed heart musculature [25].

Thus, the value of a high mutational load may be to induce immunoreactivity against multiple neoantigens and simultaneously overwhelm any shared antigen response, thereby eliminating the tumor before significant shared antigen expansion and related organ toxicity develops. Such biology might explain the enhanced durable antitumor benefit observed in patients with irAEs, despite the use of often-prolonged immunosuppressive therapy.

Ultimately, it may be possible, albeit difficult, to identify at baseline patients with expanded immunity against antigens shared by the tumor and vital host organs, so that one could take measures to minimize the organ toxicity. Alternatively one could use pre-treatment vaccination against neo-epitopes in order the steer the immune response towards tumor restricted rather than shared antigens.

This report emphasizes that while the response to ICI is significantly lower in patients with UM compared to those with CM, a major response can be achieved. Additional work is required to select the appropriate patients with UM who are destined to benefit from ICI and to determine a means of dissociating anti-tumor responses against shared antigens from toxicity to organs expressing the same antigens.

\section{Additional file}

Additional file 1: Supplemental Appendix. (DOCX $7 \mathrm{~kb})$

\section{Acknowledgements}

We thank Dr. Moutasem N Aljundi, Department of Radiology MedStar Georgetown University Hospital, for his assistance in obtaining high-resolution computed tomography images for Fig. 1.

Funding

The study was partially funded by Bristol-Myers Squibb in the analysis of data. 


\section{Availability of data and materials}

The datasets used and analyzed during the current study are available from the corresponding author on reasonable request.

\section{Authors' contributions}

$\mathrm{SR}, \mathrm{Bl}, \mathrm{CB}, \mathrm{AA}, \mathrm{MBA}$ developed conception and design. SR, DW, JCZ, AJC collected and assembled of data. SR, BI, CB, SM, PS, JMP, CJC and MBA performed data analysis and interpretation. SR carried out manuscript writing. All authors discussed the results and contributed to the final manuscript. All authors read and approved the final manuscript.

\section{Ethics approval and consent to participate}

Not Applicable.

\section{Consent for publication}

Consent for a special study and publication was obtained from the patient.

\section{Competing interests}

The authors declare that they have no competing interests.

\section{Publisher's Note}

Springer Nature remains neutral with regard to jurisdictional claims in published maps and institutional affiliations.

\section{Author details \\ 'Department of Oncology, Lombardi Comprehensive Cancer Center, Georgetown University Medical Center, 3970 Reservoir Rd NW, New Research Building Suite E 501, Washington, DC 20057, USA. ²Dana-Farber Cancer Institute, Boston, MA, USA. ${ }^{3}$ Bristol-Myers Squibb, Princeton, NJ, USA. ${ }^{4}$ Harvard Medical School-Harvard University, Boston, MA, USA. ${ }^{5}$ Medstar Georgetown University Hospital, Washington, DC, USA. ${ }^{6}$ Center for Molecular Biophysics, Biosciences Division, Oak Ridge National Laboratory, Oak Ridge, TN, USA.}

Received: 25 October 2018 Accepted: 11 February 2019 Published online: 04 March 2019

\section{ORCID iD}

Connor J. Cooper https://orcid.org/0000-0002-5527-9948

\section{References}

1. Inskip PD, Devesa SS, Fraumeni JF Jr. Trends in the incidence of ocular melanoma in the United States, 1974-1998. Cancer Causes Control. 2003;14: 251-7.

2. Cancer Genome Atlas N. Genomic classification of cutaneous melanoma Cell. 2015:161:1681-96.

3. Sharma P, Allison JP. The future of immune checkpoint therapy. Science 2015:348:56-61.

4. Larkin J, Chiarion-Sileni V, Gonzalez R, Grob JJ, Cowey CL, Lao CD, Schadendorf D, Dummer R, Smylie M, Rutkowski P, et al. Combined Nivolumab and Ipilimumab or monotherapy in untreated melanoma. N Engl J Med. 2015;373:23-34.

5. Algazi AP, Tsai KK, Shoushtari AN, Munhoz RR, Eroglu Z, Piulats JM, Ott PA, Johnson DB, Hwang J, Daud Al, et al. Clinical outcomes in metastatic uveal melanoma treated with PD-1 and PD-L1 antibodies. Cancer. 2016;122:3344-53.

6. Luke JJ, Callahan MK, Postow MA, Romano E, Ramaiya N, Bluth M, GiobbieHurder A, Lawrence DP, Ibrahim N, Ott PA, et al. Clinical activity of ipilimumab for metastatic uveal melanoma: a retrospective review of the Dana-Farber Cancer Institute, Massachusetts General Hospital, Memorial Sloan-Kettering Cancer Center, and University Hospital of Lausanne experience. Cancer. 2013;119:3687-95.

7. Piulats JM, De La Cruz-Merino L, Curiel Garcia MT, Berrocal A, Alonso-Carrión L, Espinosa E, López Castro R, Rodriguez-Abreu D, Luna Fra P, Martin-Algarra S. Phase II multicenter, single arm, open label study of nivolumab (NIVO) in combination with ipilimumab (IPI) as first line in adult patients (pts) with metastatic uveal melanoma (MUM): GEM1402 NCT02626962. J Clin Oncol. 2017:35(suppl; abstr 9533):2017.
8. Robertson AG, Shih J, Yau C, Gibb EA, Oba J, Mungall KL, Hess JM, Uzunangelov V, Walter V, Danilova $L$, et al. Integrative analysis identifies four molecular and clinical subsets in uveal melanoma. Cancer Cell. 2017;32:20420 e215.

9. Grossman RL, Heath AP, Ferretti V, Varmus HE, Lowy DR, Kibbe WA, Staudt LM. Toward a shared vision for cancer genomic data. N Engl J Med. 2016: 375:1109-12.

10. Teulings HE, Limpens J, Jansen SN, Zwinderman AH, Reitsma JB, Spuls PI, Luiten RM. Vitiligo-like depigmentation in patients with stage III-IV melanoma receiving immunotherapy and its association with survival: a systematic review and meta-analysis. J Clin Oncol. 2015;33:773-81.

11. Harbour JW, Onken MD, Roberson ED, Duan S, Cao L, Worley LA, Council ML, Matatall KA, Helms C, Bowcock AM. Frequent mutation of BAP1 in metastasizing uveal melanomas. Science. 2010;330:1410-3.

12. Alexandrov LB, Nik-Zainal $S$, Wedge $D C$, Aparicio $S A$, Behjati $S$, Biankin $A V$, Bignell GR, Bolli N, Borg A, Borresen-Dale AL, et al. Signatures of mutational processes in human cancer. Nature. 2013;500:415-21.

13. Ayers M, Lunceford J, Nebozhyn M, Murphy E, Loboda A, Kaufman DR, Albright A, Cheng JD, Kang SP, Shankaran V, et al. IFN-gamma-related mRNA profile predicts clinical response to PD-1 blockade. J Clin Invest. 2017; 127:2930-40

14. Lin JR, Fallahi-Sichani M, Sorger PK. Highly multiplexed imaging of single cells using a high-throughput cyclic immunofluorescence method. Nat Commun. 2015:6:8390.

15. Tumeh PC, Harview CL, Yearley JH, Shintaku IP, Taylor EJ, Robert L, Chmielowski B, Spasic M, Henry G, Ciobanu V, et al. PD-1 blockade induces responses by inhibiting adaptive immune resistance. Nature. 2014;515:568-71.

16. Andreatta M, Nielsen M. Gapped sequence alignment using artificial neural networks: application to the MHC class I system. Bioinformatics. 2016;32:511-7.

17. Nielsen M, Andreatta M. NetMHCpan-3.0; improved prediction of binding to $\mathrm{MHC}$ class I molecules integrating information from multiple receptor and peptide length datasets. Genome Med. 2016;8:33.

18. Bricout M, Petre A, Amini-Adle M, Bezza W, Seve P, Kodjikian L, Dalle S, Thomas L. Vogt-Koyanagi-Harada-like syndrome complicating Pembrolizumab treatment for metastatic melanoma. J Immunother. 2017:40:77-82.

19. Fierz FC, Meier F, Chaloupka K, Boni C. Intraocular inflammation associated with new therapies for cutaneous melanoma - case series and review. Klin Monatsbl Augenheilkd. 2016;233:540-4.

20. Mantopoulos D, Kendra KL, Letson AD, Cebulla CM. Bilateral Choroidopathy and serous retinal detachments during Ipilimumab treatment for cutaneous melanoma. JAMA Ophthalmol. 2015;133:965-7.

21. Witmer MT. Treatment of ipilimumab-induced Vogt-Koyanagi-Harada syndrome with oral dexamethasone. Ophthalmic Surg Lasers Imaging Retina. 2017:48:928-31.

22. Park CO, Kupper TS. The emerging role of resident memory $T$ cells in protective immunity and inflammatory disease. Nat Med. 2015;21:688-97.

23. Chan PY, Hall P, Hay G, Cohen VML, Szlosarek PW. A major responder to ipilimumab and nivolumab in metastatic uveal melanoma with concomitant autoimmunity. Pigment Cell Melanoma Res. 2017;30:558-62.

24. McLean LP, Shea-Donohue T, Cross RK. Vedolizumab for the treatment of ulcerative colitis and Crohn's disease. Immunotherapy. 2012;4:883-98.

25. Johnson DB, Balko JM, Compton ML, Chalkias S, Gorham J, Xu Y, Hicks M, Puzanov I, Alexander MR, Bloomer TL, et al. Fulminant myocarditis with combination immune checkpoint blockade. N Engl J Med. 2016;375:1749-55.

Ready to submit your research? Choose BMC and benefit from:

- fast, convenient online submission

- thorough peer review by experienced researchers in your field

- rapid publication on acceptance

- support for research data, including large and complex data types

- gold Open Access which fosters wider collaboration and increased citations

- maximum visibility for your research: over $100 \mathrm{M}$ website views per year

At $\mathrm{BMC}$, research is always in progress.

Learn more biomedcentral.com/submission 